\title{
Wear behaviour of TiAlN PVD coating on deep cryogenically treated HSS substrate
}

\author{
S. Šolić ${ }^{1 *}$, Z. Schauperl ${ }^{2}$, V. Tropša ${ }^{1}$ \\ ${ }^{1}$ University North, Department of Mechanical Engineering, J. Križanića 31b, 42000 Varaždin, Croatia \\ ${ }^{2}$ Faculty of Mechanical Engineering and Naval Architecture, University of Zagreb, I. Lučića 5, 10000 Zagreb, Croatia
}

Received 3 September 2018, received in revised form 7 June 2019, accepted 10 June 2019

\begin{abstract}
In this paper, the influence of deep cryogenic treatment of high-speed steel substrate on the hardness, friction coefficient, and wear rate in the dry sliding conditions of the TiAlN coating was investigated. The obtained results show that the substrate properties have a key effect on the properties of the coating-substrate interface, on the mechanical and tribological properties of the coating and consequently, on its behaviour in dry sliding wear conditions.
\end{abstract}

K e y words: TiAlN coating, high-speed steel, deep cryogenic treatment, microstructure, wear resistance

\section{Introduction}

High productivity and low cost are of great importance for today's highly competitive production. The application of hard coatings has enabled a longer lifetime of cutting and forming tools by reduction of friction and wear. The main advantages of hard coatings derive from the reduction in friction, lower cutting forces, and lower adhesion of the tool material to the workpiece. The increased surface hardness of the tool affects the reduction of abrasion wear. Reduction in diffusion wear is due to the chemical stability of the coating, which represents the diffusion barrier [1-3].

To meet the required properties, the coating material must have low adhesion to the workpiece material but high adhesion to the substrate material, good abrasion resistance, high chemical stability, and high hardness. Secondary requirements on the coatings are fine-grained microstructures, internal compression stress, and smooth surface.

Carbide and nitride PVD and CVD coatings have been successfully applied due to their properties for this purpose for several decades $[2,4]$.

Thin PVD coatings are due to fine-grained microstructures and large internal compressive strain more resistant to the formation of microcracks than CVD coatings. The efficiency of the PVD coated tools depends on the coating adhesion to the substrate and mechanical, thermal, and tribological properties of the coating itself but also on the properties of the workpiece material $[1,3-5]$.

The first coating used on cutting tools was the TiN coating, which is still in use today, due to its good properties. It is suitable for machining of less demanding materials at lower cutting speeds. For the machining of hard and tough materials at lower cutting speeds, the $\mathrm{Ti}(\mathrm{C}, \mathrm{N})$ coating has proven to be very good. It is characterized by low friction coefficient at low temperatures. The chip is therefore smooth and slides over the cutting edge of the tool $[1,2,4]$.

The $(\mathrm{Ti}, \mathrm{Al}) \mathrm{N}$ coating has made significant progress in the application on cutting tools because it has high hardness and, unlike $\mathrm{Ti}(\mathrm{C}, \mathrm{N})$ coatings, it has very good oxidation stability. For this reason, it is suitable for the highly abrasive materials, such as Fe-castings and Al-Si alloys, of the machining tools, whereby the high temperature of the cutting edge is developed. Unlike $\mathrm{Ti}(\mathrm{C}, \mathrm{N})$ coatings, ( $\mathrm{Ti}, \mathrm{Al}) \mathrm{N}$ has a higher friction coefficient, but lower thermal conductivity. Because of this, the removed chip particle causes large stresses on the cutting edge causing the delamination of the coating. On the other hand, ( $\mathrm{Ti}, \mathrm{Al}) \mathrm{N}$ coating keeps high hardness at high temperatures, has high oxidation resis-

*Corresponding author: e-mail address: ssolic@unin.hr 
Table 1. Chemical composition of PM S390 MC HSS

\begin{tabular}{cccccccccc}
\hline$\% \mathrm{C}$ & $\% \mathrm{Si}$ & $\% \mathrm{Mn}$ & $\% \mathrm{Cr}$ & $\% \mathrm{Mo}$ & $\% \mathrm{~V}$ & $\% \mathrm{~W}$ & $\% \mathrm{Co}$ & $\% \mathrm{Fe}$ \\
\hline 1.64 & 0.60 & 0.30 & 4.80 & 2.00 & 4.80 & 10.40 & 8.00 & Rest \\
\hline
\end{tabular}

Table 2. Heat treatment parameters

\begin{tabular}{lccc}
\hline Sample & $\begin{array}{c}\text { Austenitization } \\
\left({ }^{\circ} \mathrm{C} \mathrm{min}{ }^{-1}\right)\end{array}$ & $\begin{array}{c}\text { Deep cryogenic treatment } \\
\left({ }^{\circ} \mathrm{C} \mathrm{h}^{-1}\right)\end{array}$ & $\begin{array}{c}\text { Tempering } \\
\left({ }^{\circ} \mathrm{C} \mathrm{h}^{-1}\right)\end{array}$ \\
\hline $\mathrm{C}$ & $1130 / 6$ & - & $520 / 520 / 490 / 2$ \\
\hline $\mathrm{DCT}$ & $1130 / 6$ & $-196 / 24$ & $520 / 2$ \\
\hline
\end{tabular}

tance and is better thermal insulator than TiN coating.

For this reason, it is generally considered that the recommended cutting speed of the $(\mathrm{Ti}, \mathrm{Al}) \mathrm{N}$ coated tool is $30 \%$ higher than the one recommended for the TiN coated tool. During the machining, on the surface of the ( $\mathrm{Ti}, \mathrm{Al}) \mathrm{N}$ coated tool, a thin passive layer of aluminium oxide $\mathrm{Al}_{2} \mathrm{O}_{3}$ is formed, which protects the coating itself from further oxidation. If this layer is removed through wear, it is restored in a short time [1]. Aluminium oxide is also characterized by poor thermal conductivity, so most of the heat generated on the cutting edge is removed from the system with the chip and does not transfer to the tool. Therefore, it is the development of this thin layer of $\mathrm{Al}_{2} \mathrm{O}_{3}$ that has the biggest influence on the increase of the tool durability. Cutting mills with $(\mathrm{Ti}, \mathrm{Al}) \mathrm{N}$ coatings reported a $60 \%$ longer durability than the same with $\mathrm{Ti}(\mathrm{C}, \mathrm{N})$ coatings and three times longer than $\mathrm{TiN}$ [6-9].

Previous research has shown that the decisive importance for the efficiency of the tribo-system "substrate/coating/workpiece" belongs to the adhesion bond, i.e., the interface between the coating and the substrate material. The quality of the adhesion bond directly affects the performance of the coating in contact with the workpiece material and if the good adhesive bond is not achieved other coating properties are not revealed [1-10].

The characteristics of the coatings (thickness, chemical composition, microstructure, topography, etc.) are determined by the parameters of the deposition process (substrate temperature, plasma characteristics, deposition time, substrate pre-stress, etc.) but to a considerable extent also by the properties of the substrate material (chemical composition, microstructure, topography, load-bearing capacity, etc.) $[4]$.

The substrate material primarily affects the nucleation and growth pattern of the coating as well as its topography. As a result, the properties of the substrate material and the surface roughness are crucial for topography and adhesion of the coating and its effectiveness in application. Ultimately, the characteristics of the coating depends on its mechanical, thermal, chemical, and tribological properties [1-4].

This research aimed to investigate the effect of deep cryogenic treatment (DCT) of the high-speed steel substrate, produced by powder metallurgy, on hardness, wear resistance, and the friction coefficient of the TiAlN coating.

\section{Materials and methods}

The substrate material in this research was high-speed steel produced by powder metallurgy, commercial grade PM S390MC. The chemical composition of the investigated steel is given in Table 1.

The testing samples were disc-shaped with dimensions $\varnothing 22 \mathrm{~mm} \times 4 \mathrm{~mm}$. Heat treatment was conducted in Ipsen vacuum furnace with parameters presented in Table 2. The heat treatment process consisted of three-stage preheating: $650{ }^{\circ} \mathrm{C} / 30 \mathrm{~min}$, $850^{\circ} \mathrm{C} / 20 \mathrm{~min}, 1050^{\circ} \mathrm{C} / 15 \mathrm{~min}$ and heating to the austenitization temperature of $1130^{\circ} \mathrm{C}$ with the rate of $5^{\circ} \mathrm{C} \min ^{-1}$ from the last preheating. The duration of the austenitization was 6 min with subsequent quenching in nitrogen, $p=1.05$ bar.

After quenching, one set of samples, marked DCT, was slowly cooled at a controlled speed to the temperature of $-196^{\circ} \mathrm{C}$ and left for $24 \mathrm{~h}$, then slowly heated to room temperature and tempered at $520^{\circ} \mathrm{C}$ for $2 \mathrm{~h}$. Another set of samples, marked as group C, was tempered three times, as stated in Table 2.

After heat treatment, detailed testing of mechanical and tribological properties of high-speed steel was conducted with the characterization of the microstructure. The results were published elsewhere $[10$, 11]. The tests $[10,11]$ showed that deep cryogenic treatment influenced the microstructure of the steel, which was manifested by an increase in hardness (917 HV1 for classically treated samples and $945 \mathrm{HV} 1$ for 


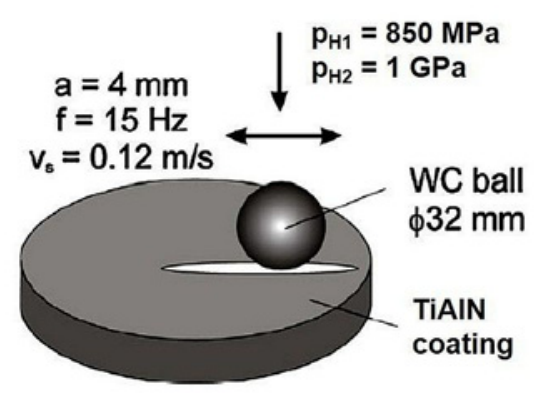

Fig. 1. "Ball-on-flat" method with testing parameters.

cryogenically treated samples), slightly increased the compressive strength and by a significant increase in galling resistance.

After the heat treatment, the samples were polished $(R a=0.05-0.10 \mu \mathrm{m})$ before coating deposition. Before the deposition of the coating, ion etching was carried out for $30 \mathrm{~min}$, with a layer thickness of about $0.1 \mu \mathrm{m}$ removed from the surface. Standard TiAlN coating was deposited at the substrate temperature of $450{ }^{\circ} \mathrm{C}$ with a thickness of $6 \mu \mathrm{m}$ using a magnetron sputtering process. The parameters and conditions of TiAlN coating deposition are described in detail in [5]. In the same work, detailed results of coating characterization are presented.

In this study, the friction coefficient and wear resistance were tested by the "ball-on-flat" method on the CSM tribotester with two applied loads of $59 \mathrm{~N}$ and $70 \mathrm{~N}\left(p_{\mathrm{H} 1}=850 \mathrm{MPa}\right.$ and $\left.p_{\mathrm{H} 2}=1 \mathrm{GPa}\right)$. The $\mathrm{WC}$ ball (Ø $32 \mathrm{~mm}$ ) was used as an oscillating counter-body with a stroke length of $4 \mathrm{~mm}$ and frequency of $15 \mathrm{~Hz}$. The test was performed at room temperature under dry sliding conditions at an average sliding speed of $0.12 \mathrm{~m} \mathrm{~s}^{-1}$ with a total sliding length of $250 \mathrm{~m}$. The test parameters are shown in Fig. 1. Three wear tracks of one-load were made on each test sample, and the result of the friction coefficient and wear volume was the mean value of three tests per load.

Wear tracks were analysed with the scanning electron microscope FE JSM6500F JEOL. The hardness of the coating was tested on a Vickers nanohardness tester, Fisherscope $\mathrm{H} 100 \mathrm{C}$, with a loading range of $0.4 \mathrm{mN}-1 \mathrm{~N}$ (40 mg to $100 \mathrm{~g}$ ), using two different loads 50 and $100 \mathrm{mN}$, respectively. Before the hardness testing the samples were polished with diamond paste $(\varnothing 1 \mu \mathrm{m})$. Applied loads in the hardness test were selected based on the depth of indentation due to the thickness of the coating so that the depth of the indentation did not exceed one-tenth of the thickness of the coating to give real hardness of the coating without affecting the hardness of the substrate on the result of the test. Ten measurements were made for each load, and the result represents their mean value.
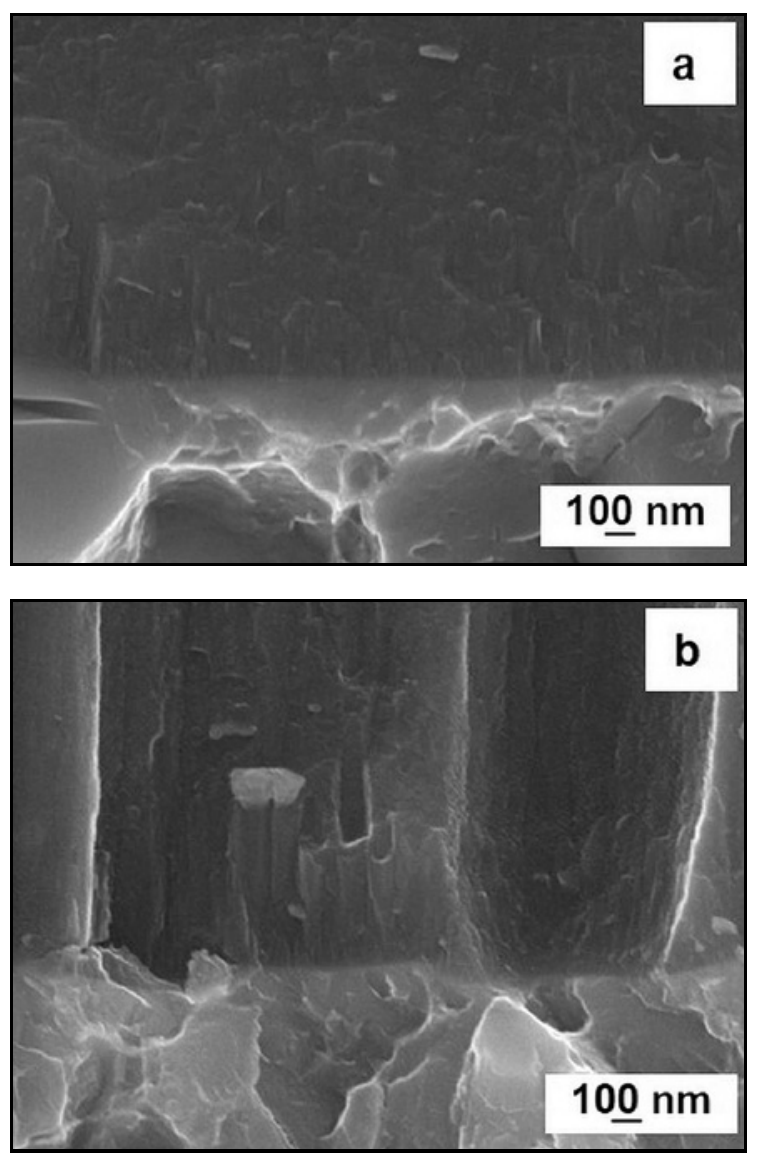

Fig. 2. Cross-section of the samples: (a) sample C and (b) sample DCT.

\section{Results and discussion}

Figure 2 shows the microstructure of the TiAlN coating on the cross-section of the test specimen. The images show TiAlN coating on the high-speed steel substrates and the uniform coating growth on both substrates. The results of the microstructure characterization of the coating with the mechanical and tribological properties of the coating are presented in [5].

The diagram in Fig. 3 shows the results of the nanohardness measurement of the TiAlN coating deposited on two differently heat-treated substrates. From the results, it can be seen that in the samples that are deep cryogenically treated, TiAlN coating has higher nanohardness for both applied loads.

The nanohardness of the coating does not represent its intrinsic property. It depends on several influencing factors $[2,4]$. The substrate properties affect the growth of the coating, its microstructure, and adhesion to the substrate. The test results show that deep cryogenic treatment of high-speed steel substrate has a significant impact on the nanohardness of the coating. According to [12], the biggest impact of DCT can be attributed to plastic deformation of primary 


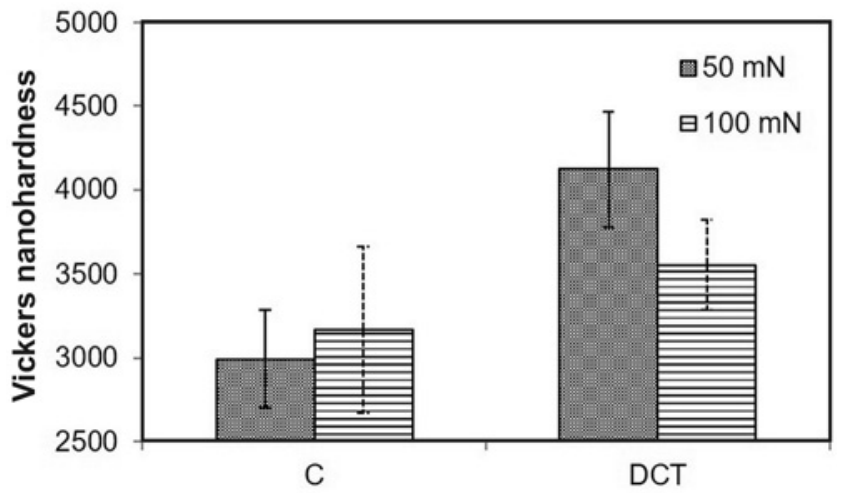

Fig. 3. Vickers nanohardness of the TiAlN coating.

martensite accompanying martensitic transformation, the partial dissolution of the carbide particles and the formation of carbon clusters. It is then assumed that the plastic deformation of the primary martensite combined with the reduced carbon content in the martensite and the precipitation of homogeneous carbides of small dimensions affect the increase in hardness in the DCT sample, which has also influenced the

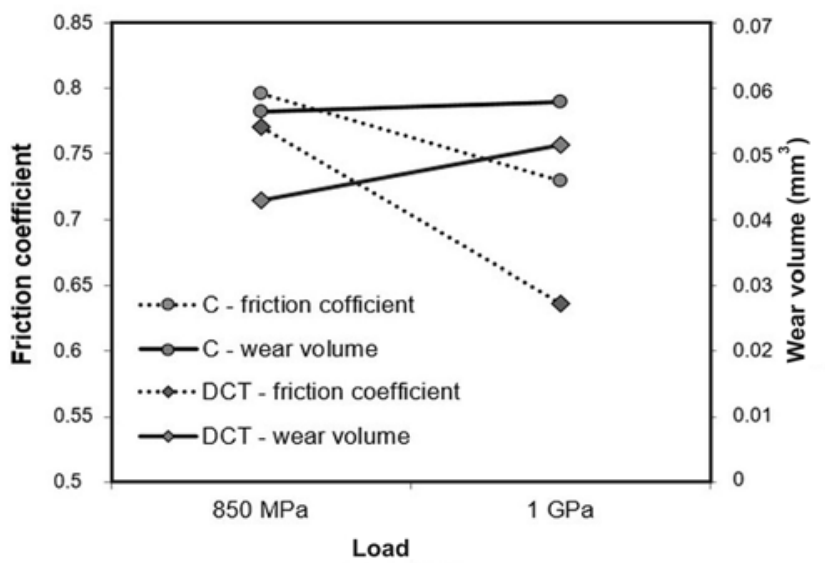

Fig. 4. Wear volume and the friction coefficient of the TiAlN coating.

enhancement of the nanohardness of the TiAlN coating on DCT substrate. Authors in [13] assumed that the amount of dissolved carbon in the martensite and finer and more homogeneous carbides precipitation increase the fracture toughness/high hardness ratio of the high-speed steel substrate. That also affects the
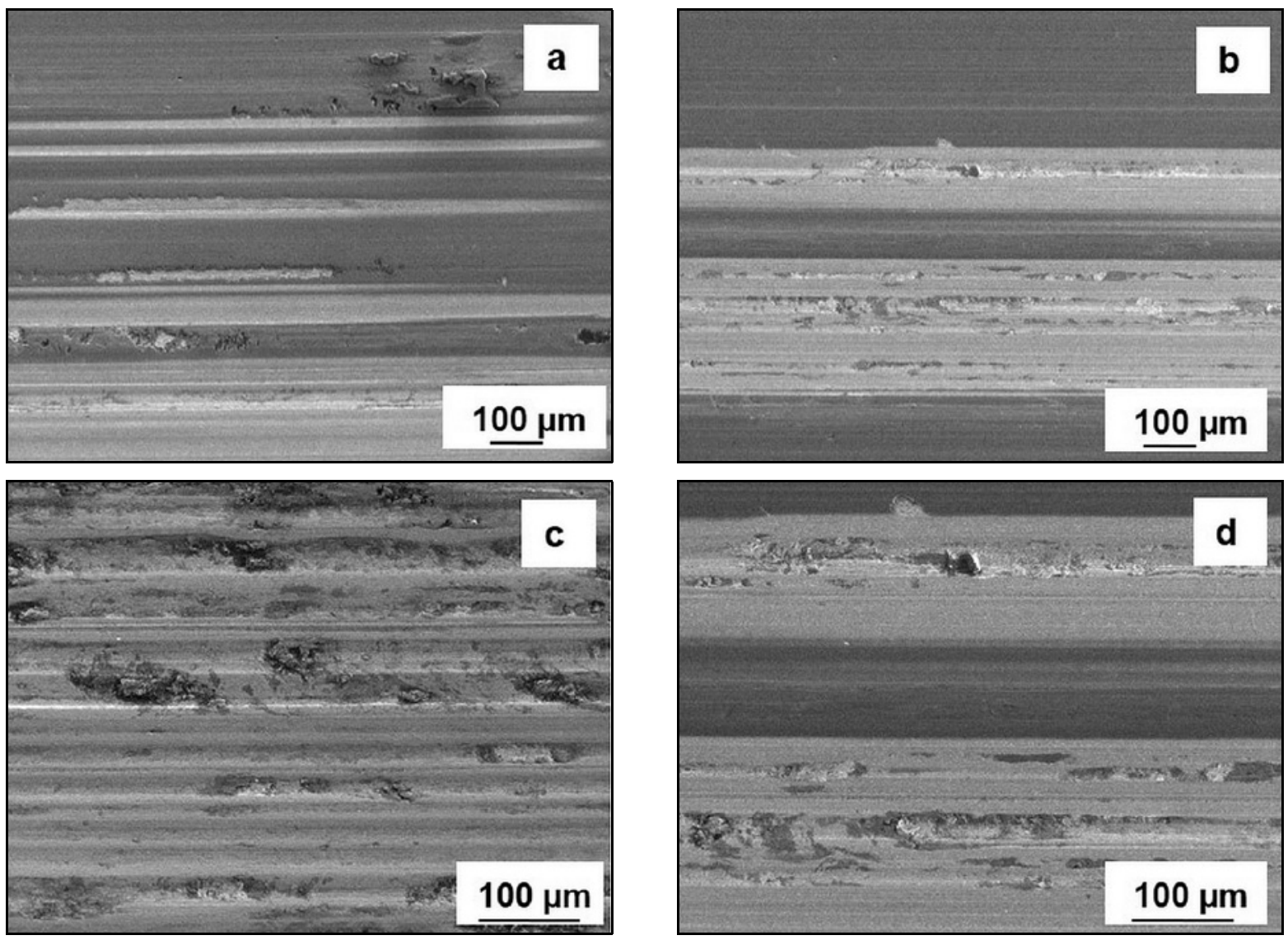

Fig. 5. Wear tracks on the TiAlN coating at the applied load of $850 \mathrm{MPa}$ : (a) and (c) sample C different magnification; (b) and (d) sample DCT different magnification. 

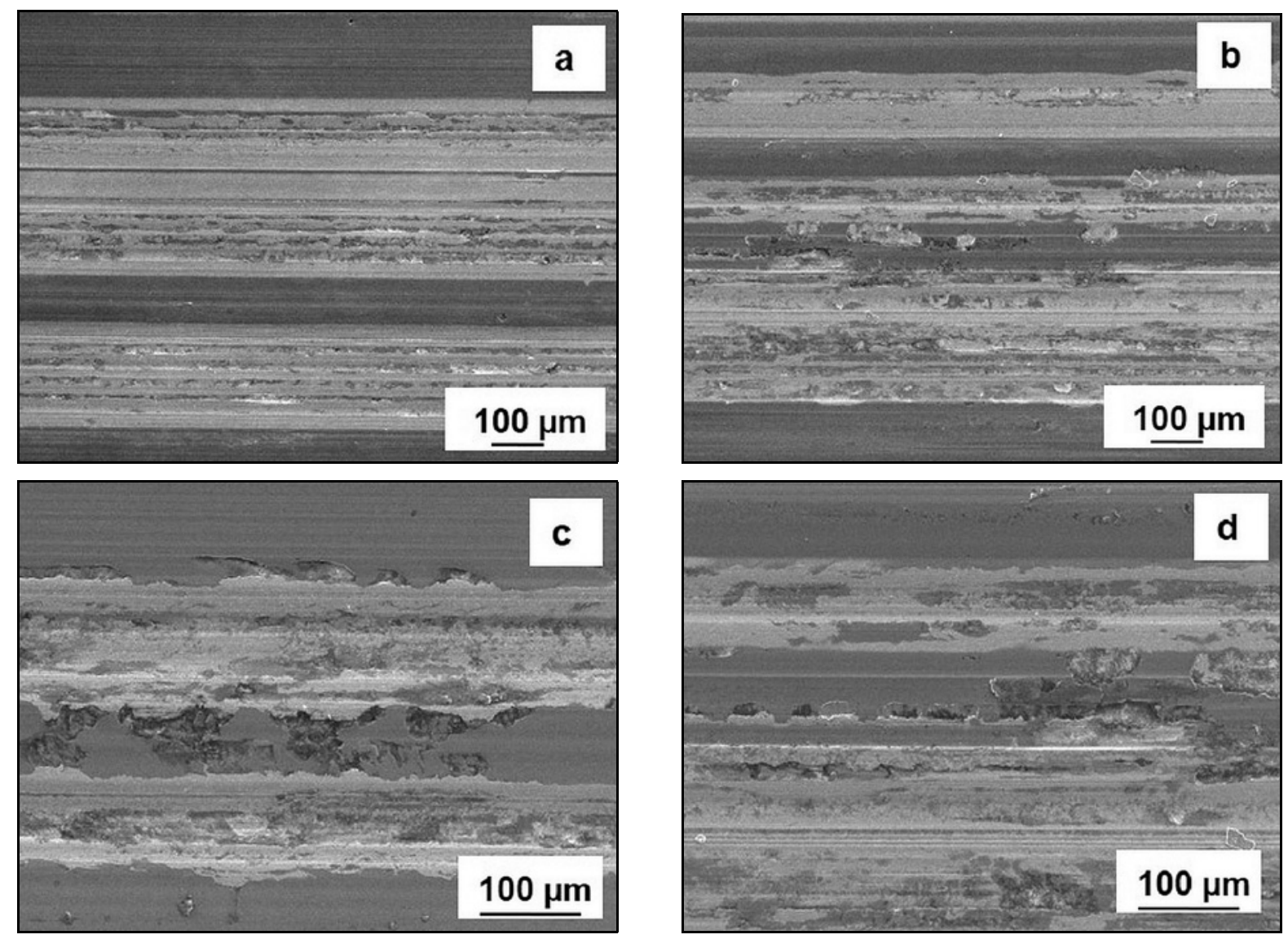

Fig. 6. Wear tracks on the TiAlN coating at the applied load of 1 GPa: (a) and (c) sample C different magnification; (b) and (d) sample DCT different magnification.

load bearing capacity of the substrate, and more homogeneous carbides precipitation affect the growth of the coating since the coating topography reflects the protruding carbides of the substrate formed during ion etching [14].

The results of the ball-on-flat wear test are shown in the diagram in Fig. 4. The test results show that DCT of high-speed steel substrate has affected the reduction of the TiAlN coating friction coefficient under dry sliding conditions for both applied loads, with a friction coefficient decrease with an increase in load. The wear volume of the TiAlN coating in dry sliding conditions is also lower on the DCT sample. With the increase in test load, the wear volume of the coating increased, but the wear volume on the DCT sample was $10 \%$ lower compared to the classically heat-treated sample.

The properties of the substrate material can have a significant influence on the load-bearing capacity of the coating/substrate interface, and it can affect the reduction of coating wear as shown in several papers [13-19].

For determining the wear mechanisms that appeared on a particular sample, the wear tracks were analysed by FE SEM. Figure 5 shows wear tracks of test specimens under the dry sliding conditions at a contact pressure of $850 \mathrm{MPa}$. In Figs. 5a,c of sample $\mathrm{C}$ (standard heat treatment), micro cuttings and micro ploughing of the coating surface can be observed, which indicates both mild and severe abrasion wear during the test and it is apparent that there was the formation of the ridge, which also indicates the appearance of adhesion wear. At higher magnification micro-cracks of the coating surface are also visible. On DCT sample (Figs. 5b,d), it is apparent that wear tracks are consistent with the mild abrasion and are not as severe as in sample $\mathrm{C}$, which is consistent with the smaller friction coefficient this coating has had during this test, and with a lower wear volume achieved. The wear track analysis showed only traces of abrasive wear appearance but without the significant appearance of the adhesion mechanism and the formation of ridges or traces of plastic deformation. The crack formation on sample $\mathrm{C}$ is consistent with [2] and the hardness test results, as it has been shown that increasing the hardness of the substrate increases the load that the coating can withstand without cracking due to the increase of the coating resistance to deformation [2].

Figure 6 shows wear tracks of test specimens under 
dry sliding conditions at $1 \mathrm{GPa}$ contact pressure. Figure 6 shows that DCT sample (Figs. 6b,d) also showed more intense wear tracks with the appearance of adhesion mechanism, visible areas with deformation of the coating and the formation of ridges. Also, delaminated coating particles are visible as well as the appearance of micro-cracks. In sample C (Figs. 6a,c) signs of intensive abrasive and adhesive wear mechanism can be seen along the areas from which the coating was removed, and the intensely plastically deformed areas. Plastically deformed areas in the wear tracks are also visible on the DCT sample. In case of bigger loads in the sliding conditions on the surface of the hard coating, the friction resulting from the shearing of the coating and the formation of the groove results in tensile stress behind the ball along with the compressive stress and the build-up of the material in front of the ball [2]. The intense sliding of the ball on the coating surface in such conditions results in the plastic deformation and the smoothing of the wear tracks, as can be seen in Fig. 6 .

\section{Conclusions}

The influence of deep cryogenic treatment of high-speed steel substrate on the hardness, friction coefficient, and wear rate in dry sliding conditions of the TiAlN coating was investigated. The presented results show that deep cryogenic treatment of the substrate material influences the properties of TiAlN coating. The hardness of the coating measured with the $50 \mathrm{mN}$ load on the DCT substrate is almost $25 \%$ higher than the coating hardness on the classical heat-treated samples, and at the load of $100 \mathrm{mN}, 12.5 \%$, respectively. In dry sliding wear conditions, DCT of the substrate influenced the reduction in friction coefficient by approximately $15 \%$ with an applied load of $1 \mathrm{GPa}$. Wear volume of DCT sample decreases by $30 \%$ at lower applied load, and approximately by $15 \%$ at higher applied load comparing to the classically treated sample. The results of the wear track analysis showed the presence of the combined mechanisms of mild and severe abrasion, and also the adhesion wear, which were more extensive on the classically heat-treated samples.

\section{References}

[1] Solić, S.: Influence of the High Speed Steel Microstructure on Tribological Properties of Cutting Tools. [Doctoral Thesis]. Zagreb, University of Zagreb 2011. (in Croatian)
[2] Holmberg, K., Matthews, A.: Coatings Tribology. Amsterdam, Elsevier Science B. V. 1994.

[3] Soković, M., Barišić, B., Sladić, S.: Journal of Materials Processing Technology, 209, 2009, p. 4207. doi:10.1016/j.jmatprotec.2008.11.026

[4] Panjan, P., Cekada, M.: Protection of Tools with Hard PVD Coatings. Ljubljana, Jožef Stefan Institute 2005. (in Slovenian)

[5] Šolić, S., Cajner, F., Panjan, P.: Materials Science and Engineering Technology, 44, 2013, p. 950. doi:10.1002/mawe.201300168

[6] Jindal, P. C., Santhanam, A. T., Schleinkofer, U., Shuster, A. F.: International Journal of Refractory Metals \& Hard Materials, 17, 1999, p. 163. doi:10.1016/S0263-4368(99)00008-6

[7] Kalss, W., Reiter, A., Derflinger, V., Gey, C., Endrino, J. L.: International Journal of Refractory Metals \& Hard Materials, 24, 2006, p. 399. doi:10.1016/j.ijrmhm.2005.11.005

[8] Dobrzanski, L. A., Pakuła, D., Križ, A., Soković, M., Kopač, J.: Journal of Materials Processing Technology, 175, 2006, p. 179. doi:10.1016/j.jmatprotec.2005.04.032

[9] Wang, D. Y., Chang, C. L., Wong, K. W., Li, Y. W., Ho, W.-Y.: Surface and Coatings Technology, 120-121, 1999, p. 388. doi:10.1016/S0257-8972(99)00452-1

[10] Solić, S., Cajner, F., Leskovšek, V.: Materials Testing, 10, 2012, p. 688. http://www.hanser-elibrary.com/ doi/abs/10.3139/120.110380

[11] Solić, S., Schauperl, Z., Godec, M., Tropša, V.: Tehnički Glasnik, 11, 2017, p. 166.

[12] Tyshchenko, A. I., Theisen, W., Oppenkowski, A.: Materials Science and Engineering A, 527, 2010, p. 7027. doi:10.1016/j.msea.2010.07.056

[13] Podgornik, B., Paulin, I., Zajec, B., Jacobson, S., Leskovšek, V.: Journal of Materials Processing Technology, 229, 2016, p. 398. doi:10.1016/j.jmatprotec.2015.09.045

[14] Panjan, P., Drnovšek, A., Kovač, J.: Surface \& Coatings Technology, 343, 2018, p. 138. doi:10.1016/j.surfcoat.2017.09.084

[15] Huang, X., Etsion, I., Shao, T.: Wear, 338-339, 2015, p. 54. doi:10.1016/j.wear.2015.05.016

[16] Rousseau, A. F., Partridge, J. G., Mayes, E. L. H., Totona, J. T., Kracica, M., McCulloch, D. G., Doyle, E. D.: Surface \& Coatings Technology, 272, 2015, p. 403. doi:10.1016/j.surfcoat.2015.03.034

[17] Podgornik, B., Sedlaček, M., Cekada, M., Jacobson, S., Zajec, B.: Surface \& Coatings Technology, 277, 2015, p. 144. doi:10.1016/i.surfcoat.2015.07.021

[18] Amini, K., Akhbarizadeh, A., Javadpour, S.: Kovove Mater., 54, 2016, p. 331. doi:10.4149/km_2016_5_331

[19] Madej, M., Ozimina, D., Kurzydłowski, K., Płociński, T., Wiecinski, P., Baranowicz, P.: Kovove Mater., 54, 2016, p. 185. doi:10.4149/km_2016_3_185 